\title{
AUVs: designing and operating next generation vehicles
}

\author{
Gwyn Griffiths* \\ Southampton Oceanography Centre, UK \\ Ian Edwards, \\ Subsea7 Ltd., UK
}

\begin{abstract}
Over the last decade Autonomous Underwater Vehicles (AUVs) have become capable marine platforms. AUVs built in Europe are now operational tools in the global offshore business. Industry has seen significant cost savings from this new technology. Data quality has improved to the point where some customers in the offshore industry now prefer not to use shipboard systems. But what of AUVs for operational oceanography? Is the successful collaboration between research and industry in the offshore business a transferable model? This paper examines AUVs in scenarios relevant to EuroGOOS against the capabilities of existing technologies and those under development.
\end{abstract}

\section{Keywords}

Autonomous vehicles, survey, technology

\section{Introduction}

It is an oft-stated truism that in many branches of oceanography our progress in understanding is limited by our capacity to make observations on suitable time and space scales (e.g. Dickey, 2002; Fisher and Flemming, 2002). For over a decade, the autonomous underwater vehicle (AUV) has been promoted as one option, of many, that might lead to a significant increase in our data-gathering capacity. Now that AUVs are accepted tools with the ocean research, commercial seafloor survey, subsea mineral exploration and defence communities, it is timely to review their potential as tools to aid the data-gathering needs of operational oceanography.

Many research groups in Europe and North America have access to mature AUV technology incorporated in vehicles that are capable of performing science missions of real utility. The Autosub project (Millard et al., 2003) is a leading example of a large (ca. 1.5 tonne) AUV that has provided new insights into areas of oceanography as diverse as the ecology of krill in the Southern Ocean, fish stock assessment in the North Sea, the distribution of turbulence within organised flow structures in the upper ocean, sea ice thickness distribution in the Weddell Sea; the flow over the sill between the eastern and western Mediterranean Sea and the small scale distribution of different species of phytoplankton near the sea surface. While the Autosub has been successful at adding to our knowledge of the ocean, this has been through process study experiments,

\footnotetext{
* Corresponding author: Southampton Oceanography Centre, Empress Dock, Southampton SO14

3ZH UK. Email: gxg@ soc.soton.ac.uk
} 
and not, as yet, through the provision of 'operational' data, for example as envisaged in the GOOS 1998 Prospectus (p. 49 in IOC, 1998). This situation looks set to continue, at least over the next three years. The same seems true for other large research AUVs.

In contrast, major companies in the offshore energy industry have embraced medium and large-sized AUV technology as a key solution to gathering high quality operational data in the deep ocean (below $400 \mathrm{~m}$ ) at a significant cost saving over previous methods, that is, surface ships and deep-tow vehicles (Danson, 2003). While the offshore energy industry lagged behind the science community in driving the development of AUVs until the late 1990's, the subsequent pace of transition from demonstration trials to routine operations has been remarkable (Hill, 2002).

Research groups and companies in Europe have also pioneered the use of small AUVs for coastal and shallow water applications. They are considerably less expensive than large AUVs, require much smaller support teams, and are far easier to deploy and recover, but have a shorter range. Within SUMARE, an EU-FP5 funded project, the AUV Mauve has been used for bathymetric survey of sand exploitation in Belgian coastal waters. Mauve is a reconfigurable torpedo-like vehicle, $1.80 \mathrm{~m}$ long, weighing $\sim 30 \mathrm{~kg}$ in air, with a scientific payload space available for specific instrumentation (Figure 1a). Using innovative adaptive sampling Mauve, through specific guidance algorithms, can decide for itself, using the acquired data, where is the more appropriate place, and what is the best way to sample, to achieve the objective of the mission.

Another small European AUV that is operational is the Gavia (Thorhallsson and Hardason, 2002). In addition to a CTD the Gavia can carry cameras, lights and sonar and has been used to investigate the effect on the benthos of new fishing gear and in studies of marine ecosystems. It is easily deployed from a small boat (Figure 1b).
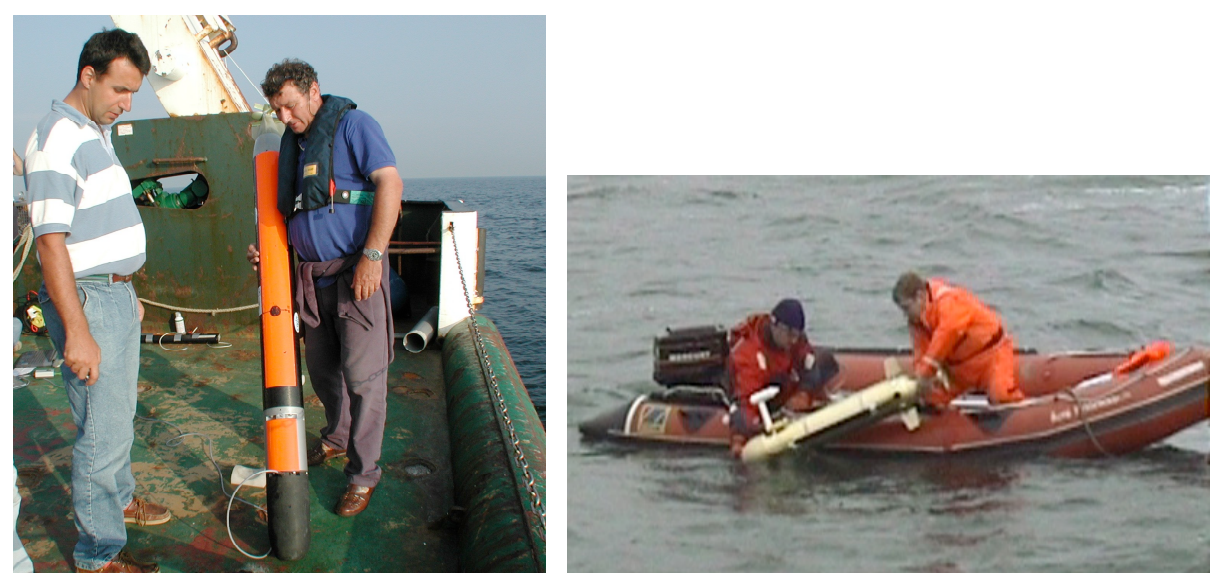

Figure 1 Small AUVs are easily deployed: left: the Mauve AUV ready for a North Sea deployment, right: the Gavia vehicle being deployed from a small boat.

The central tenet of this paper is that designing and operating next generation AUVs for operational oceanography is primarily a challenge for the business model rather than for 
the technology. While improvements in technology are required in several areas, they do not present a barrier to the adoption of AUVs within an operational data gathering system. The remainder of this paper is organised as follows: Section 2 describes the change processes within the offshore energy industry that led to the rapid adoption of AUV technology. Section 3 presents some costed scenarios for using autonomous underwater vehicles as data-gathering platforms for operational oceanography in Europe. Some conclusions are drawn in Section 4.

\section{Drivers for operational AUVs in offshore industry}

Several research groups world-wide were developing AUVs for marine science applications by the early 1990's. By the middle of the decade, these groups had gained a great deal of experience with autonomous vehicles. Yet, as late as 1995, many within the offshore energy industry were dismissing the new technology. It is apposite to quote one such response, given at a meeting convened by the UK Society for Underwater Technology ('The Potential of Robotic Systems in the Seas and Offshore') to bridge the gap in vision that then existed between marine researchers and those in offshore energy: 'Mr X gave what was perhaps the most firm rebuff of the day to the notion of using AUVs in industry' (Stevenson, 1995).

However, by 1999 the situation was completely different. Marine technologists had persevered with AUVs, had designed, built and operated vehicles in the open ocean, and, of critical importance, survey sensors were becoming available that could be carried within the payload space of AUVs. Combined with the advances that had taken place in navigation systems for autonomous vehicles, key individuals in the offshore energy industry began to explore seriously the potential benefits of the new technology.

Shell International Exploration and Production BV's 'Gamechanger' project report in February 1999 was a major milestone. For the first time, end-users in the offshore energy business made available to their suppliers (but only their suppliers) an analysis of the effect that this new technology could have on its operations within 5 years (that is, to 2004). The report's main conclusions were later made public (Gallett, 1999):

- Survey Class AUVs whose tasks would include seabed survey, pipeline route surveys and inspections, oceanographic and environmental data collection, at water depths ranging from $100 \mathrm{~m}-4000 \mathrm{~m}$ were feasible within 1-2 years (that is, during 2000-2001).

- Work Class AUVs, designed for intervention, using manipulators and operating within and around structures, were not feasible before 2004.

- Hybrid ROV/AUV vehicles, combining a work class ROV with AUV modules, was feasible before 2004.

Following from these conclusions, the report estimated that 'operational cost savings of over $\$ 30 \mathrm{M}$ and increased leverage of over $\$ 75 \mathrm{M}$ are in prospect within 5 years'. In effect, this was a green light from a major customer for the service provider companies to invest in providing the new technology.

An analysis along the lines of the Shell Gamechanger project does not seem to have been carried out by the customers that pay or commission data acquisition within the realm of EuroGOOS. Hence the reluctance of service providers to invest in the capacity to make those observations is understandable. The following section presents, for debate, examples of what could be done by existing and next generation vehicles, with some indication of costs. 


\section{Scenarios for AUVs in European operational oceanography}

The technical maturity of current generation autonomous underwater vehicles, as described in the chapters within Griffiths (2003), is sufficient to tackle many tasks of value to the European operational oceanography community and their end-users. Nevertheless, some aspects of vehicle design and, perhaps more important, aspects of overall system design and cost do need to be tackled. Three examples are developed below to illustrate the possibilities and the challenges.

\subsection{Exchanges between the Arctic/Nordic Seas and the North Atlantic.}

The section from Scotland to the Faroe Islands, to Iceland and on to Greenland is key to understanding the meridional overturning circulation of the North Atlantic (Saunders, 2001). Some parts of the section have been observed over many years by cruises and moored instruments, other parts less frequently. Severe weather can preclude or curtail observations from ships in winter. How might an AUV substitute?

- Type of AUV - the section traverses areas of strong currents where buoyancydriven vehicles (gliders) with their slow forward speeds $\left(\sim 0.3 \mathrm{~m} \mathrm{~s}^{-1}\right)$ would be subject to excessive drift. The range exceeds that of small AUVs, leaving large AUVs as the most appropriate technology.

- Range - a section from Scotland, over the Wyville Thomson Ridge, over the Faroe Bank, crossing the Faroe Bank Channel to the Faroe Islands is $360-400 \mathrm{~km}$. This is achievable with today's larger propeller driven AUVs. Launch and recovery could be from shore bases. From the Faroe Islands to Iceland along the Iceland Faroe Ridge is about $440 \mathrm{~km}$. From Iceland to Greenland, and return, is about $600 \mathrm{~km}$, which could be achieved with little technical difficulty. Multiple stages, that is Scotland to Iceland without refuelling at the Faroe Islands, would require a range capability beyond the cost-effective capability of today's vehicles, but could be achieved within three years based on planned development of lithium-ion batteries.

- Depth - the maximum sill depth on this section of $840 \mathrm{~m}$ in the Faroe Bank Channel is well within the specification of a number of AUVs. Profiles would be obtained every $2 \mathrm{~km}$ i.e. $~ 800$ profiles over the two-way section.

- Sensor requirements - Sensors pose few difficulties in this application. Standard CTDs would be used. The calibration stability of the conductivity sensor would be less of an issue compared to profiling floats as large AUVs can carry water samplers and the duration of each mission would be measured in days. Absolute currents could be measured with ADCPs. Although not yet used in an AUV, $75 \mathrm{kHz}$ phased array ADCPs could be installed if the pressure rating of the acoustic transducer could be increased. These instruments would enable bottom tracking, hence absolute currents, over the entire section even when the vehicle was near the surface. Additional sensors, already proven within AUVs, would include fluorometerers for chlorophyll, electrodes for dissolves oxygen, transmissometers, UV absorption for dissolved nitrate, microsensors for turbulence (heat and velocity) and even fisheries echo-sounders (Langebrake, 2003).

- Navigation - with a bottom tracking ADCP for speed over ground and a fiber-optic gyrocompass for heading, with the vehicle surfacing twice a day for GPS fixes the position error would be less than $350 \mathrm{~m}$ between fixes. This would be adequate for the type of survey envisaged above. 
Table 1 Schedule and cost of a monthly AUV occupation of the Scotland-Iceland section.

\begin{tabular}{llcc}
\hline $\begin{array}{l}\text { Day of } \\
\text { month }\end{array}$ & Activity & $\begin{array}{c}\text { Vehicle lease \& } \\
\text { insurance cost ( })\end{array}$ & $\begin{array}{c}\text { Other cost } \\
(\text { ) }\end{array}$ \\
\hline $1-4$ & Preparation at Stornoway & 8,800 & 8,200 \\
$5-7$ & AUV on passage to Torshavn & 6,600 & - \\
$8-9$ & Retrieval, refuelling, inspection, & 4,400 & 7,600 \\
& remove samples and redeploy & & - \\
$10-12$ & AUV on passage to Seydisfjord & 6,600 & 7,600 \\
$13-14$ & Retrieval, refuelling, inspection, & 4,400 & - \\
& remove samples and redeploy \\
$15-17$ & AUV on passage to Torshavn & 6,600 & 7,600 \\
$18-19$ & Retrieval, refuelling, inspection, & 4,400 & - \\
& remove samples and redeploy & & 1,000 \\
$20-22$ & AUV on passage to Stornoway & 6,600 & 32,000 \\
$23-30$ & Retrieval, contingency period & 17,600 & - \\
& & 66,000 & Total
\end{tabular}

The vehicle would require bases at Stornoway (Scotland), Torshavn (Faroe Islands), and Seydisfjord (Iceland). The procedures for shore-based launch and recovery assisted by a small inshore boat have already been established (Griffiths et al., 1998).

Table 1 shows a schedule for an AUV occupying this section, performing east to west and west to east transects on a monthly basis from Scotland to Iceland and return. The cost has been derived as follows. We assume that the AUV can be leased for 2,000 a day, given a long lease, and that insurance will cost 200 a day. Each deployment and recovery by small boat is estimated to cost 1,000 and each shore preparation involves travel and attendance by two engineers ( 2,600-4,200). The energy and maintenance cost per leg is estimated at 3,000, based on using secondary Lithium-Ion batteries. The total monthly cost of 98,000 compares to an estimated cost of $\sim 275,000$ for occupying the section using an ocean-going research ship ${ }^{1}$ with a larger station spacing.

\subsection{Trans-Mediterranean section}

It is within the current capability of more than one AUV to carry out repeat hydrographic sections across the Mediterranean Sea if a refuelling stop is available. As an example, the section from Toulon (France) to Oran (Algeria) and return could be occupied on a monthly basis given refuelling at Mallorca. Figure 2 shows a cross section of salinity from the OCCAM $1 / 12 \times 1 /{ }^{\circ}$ global ocean model along the track indicated in the inset map. The salinity shown is an instantaneous, winter-time field such as may be observed by a near-synoptic AUV survey. The maximum depth of $\sim 2800 \mathrm{~m}$ is achievable with existing vehicles and Mallorca is almost midway between the two end-points - each leg would be $\sim 500 \mathrm{~km}$. On the same cost basis as in Table 1, the cost of a mission from Toulon to Oran and return would be $\sim 99,300$.

1275,000 is calculated as follows: assuming a $10 \mathrm{~km}$ station spacing, providing 166 stations, with each station taking 1 hour, a vessel speed between stations of $16 \mathrm{~km} \mathrm{hr}^{-1}$ with one day for mobilisation, one day for demobilisation gives a duration of 13 days. The research ship cost is estimated at 18,000 per day based on actual figures for RRS Charles Darwin and Discovery, and the cost of on-board technical and scientific support is estimated at 3,000 per day. 


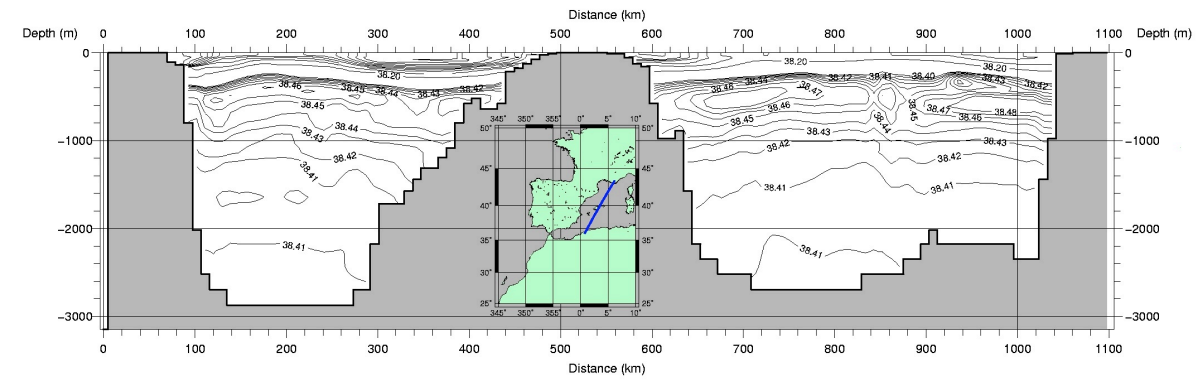

Figure 2 A cross section of salinity from the OCCAM $1 / 12 \times 1 / 12$ global ocean model along the track indicated in the inset map. Africa is on the left, France on the right and the section crosses the island of Mallorca.

\subsection{Transects of the Mediterranean outflow}

Figure 3 shows an instantaneous, winter-time salinity section from the OCCAM $1 / 12 \mathrm{x}$ $1 / 12$ global ocean model between Africa, near El Aaiún (Western Sahara) and ending in Portugal, near Lisbon. The track is indicated in the inset map. This section slices through the tongue of high salinity water resulting from the Mediterranean outflow (right). Some of this high salinity water detaches from the Iberian coast as sub-surface eddies. Such mesoscale features are intermittent and difficult to sample with traditional ship-based instruments. Regular transects by AUVs could be used to good effect.

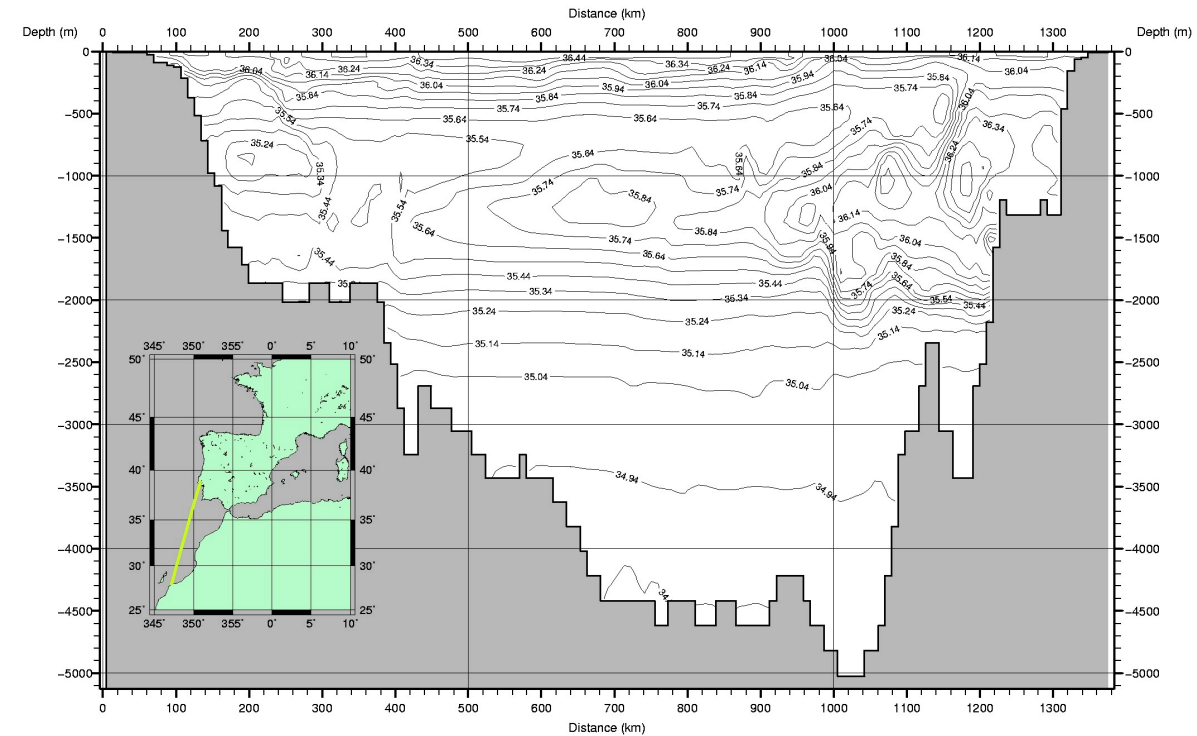

Figure 3 An instantaneous, winter-time salinity section between Africa (left) and Portugal (right) from the OCCAM $1 / 12 \times 1{ }^{1}$ global ocean model. The track is indicated in the inset map. 
The outflow of high salinity water from the Mediterranean has an impact on the regional and global ocean circulation (Candela, 2001). Programmes such as CANNIGO have improved our understanding of the physics of the area, but routine in situ monitoring may have a place in future plans. If so, the requirements in terms of depth and range would require the capabilities of the next generation of AUVs. No AUV available today has the necessary combination of range and endurance. The range required $(\sim 1400 \mathrm{~km})$ is within the endurance of gliders such as Spray, Seaglider and Slocum (Davis et al., 2003), but these gliders are limited currently to operate at depths of less than $1500 \mathrm{~m}$, barely adequate to reach the lower part of the Mediterranean overflow. Several large propeller-driven AUVs in routine use today would not be able to reach the maximum depth of $\sim 5000 \mathrm{~m}$ but would be able to reach $3000 \mathrm{~m}$ and hence the lower part of the overflow. However, they do not have the endurance. The Odyssey AUV, which uses glass spheres for buoyancy, has an adequate depth rating, but its endurance is far short of what's required. Given direction and encouragement, marine technologists could provide AUVs with the combination of range and endurance within five years.

\section{Conclusions}

Using examples from the applications of autonomous underwater vehicles in marine scientific process experiments and their recent success in providing efficient routine surveys for the offshore industry we have shown that it is no longer technology that is holding back the use of these vehicles in operational oceanography. Vehicles existing today could tackle sections such as Scotland to Iceland and France to Algeria with midsection refuelling. The cost of occupying such sections with AUVs is significantly less than when using a research ship. Technology developments will be needed, in terms of range and depth, before AUVs will be able to tackle sections such as Portugal to Africa (or the Canary Islands) across the Mediterranean outflow. Docking stations for AUVs are being developed that would allow battery recharging and download of data without the need for recovery. When these stations become available, the cost of mid-section refuelling could reduce and the risk of damage to the vehicle could also reduce, as recovery remains the most difficult operation with an AUV.

Debate on the introduction of AUVs into operational oceanography should centre on the scientific requirement in the context of cost, with close dialogue between scientists and engineers on turning requirements into practical vehicles.

\section{Acknowledgements}

We are grateful to Alain Norro of MUMM for the description and photograph of the Mauve vehicle and Torfi Thorhallsson of Hafmynd for details of Gavia. Andrew Coward of the OCCAM large scale modelling team at SOC kindly produced the simulated AUV sections in Figures 2 and 3, hinting at the powerful combination of model and AUV.

\section{References}

Candela, J., 2001, Mediterranean water and global circulation, pp. 419-429 in Ocean Circulation and Climate, Siedler, G., J Church and J. Gould (eds), Academic Press, London. 
Danson, E.F.S., 2003, AUV tasks in the offshore industry, pp. 127-138 in Technology and Applications of Autonomous Underwater Vehicles, Griffiths, G. (ed). Taylor and Francis, London.

Davis, R.E., C.C. Eriksen and C.P. Jones, 2003, Autonomous buoyancy-driven underwater gliders, pp. 37-58 in Technology and Applications of Autonomous Underwater Vehicles, Griffiths, G. (ed). Taylor and Francis, London.

Dickey, T.D., 2002, A vision of oceanographic instrumentation and technologies in the early twenty-first century, pp. 209-254 in Oceans 2020 - Science, Trends and the Challenge of Sustainability, Field, J.G., G. Hempel, and C.P. Summerhayes (eds). Island Press, Washington D.C.

Fisher, J. and N.C. Flemming, 2002, The EuroGOOS data requirements survey, pp. 3544 in Operational Oceanography - Implementation at the European and Regional Scales, Proc. $2^{\text {nd }}$ International Conference on EuroGOOS. Elsevier, Amsterdam.

Gallett, I.N.L., 1999, \$10 Oil: Is underwater robotics an answer? Report of a workshop on AUVs and other underwater robotics, SUT, London.

Griffiths, G., McPhail, S.D., Rogers, R. and Meldrum, D.T., 1998. Leaving and returning to harbour with an autonomous underwater vehicle. Proceedings Oceanology International '98, Brighton, Vol. 3, pp. 75-87, Spearhead Exhibitions Ltd, New Malden, ISBN 0900254238.

Griffiths, G., 2003, Technology and Applications of Autonomous Underwater Vehicles, Taylor and Francis, London.

Hill, A., 2002, AUV uptake in the offshore industry: maintaining a forward momentum, Proc. Unmanned Underwater Vehicle Showcase 2003, p. 1, Spearhead Exhibitions, New Malden, UK.

IOC, 1998, The GOOS Prospectus 1998, Intergovernmental Oceanographic Commission, Paris.

Langebrake, L.C., 2003, AUV sensors for marine research, pp. 245-278 in Technology and Applications of Autonomous Underwater Vehicles, Griffiths, G. (ed). Taylor and Francis, London.

Millard, N.W. et al., 2003, Multidisciplinary ocean science applications of an AUV: the Autosub science missions programme, pp. 139-160 in Technology and Applications of Autonomous Underwater Vehicles, Griffiths, G. (ed). Taylor and Francis, London.

Saunders, P.M., 2001, The dense northern overflows, pp. 401-418 in Ocean Circulation and Climate, Siedler, G., J Church and J. Gould (eds), Academic Press, London.

Stevenson, P., 1995, The potential of robotic systems in the seas and offshore - Report on the Collquium, Underwater Technology, 21(2), pp. 44-46.

Thorhallsson, T and H. Hardason, 2002, GAVIA - a modular compact AUV for deep and shallow waters, Proc. Unmanned Underwater Vehicle Showcase 2003, pp. 4558, Spearhead Exhibitions, New Malden, UK. 